\title{
Implementasi HOT-Fit Model Dalam Evaluasi Perpustakaan Digital Universitas PGRI Madiun
}

\author{
Ridho Pamungkas \\ Program Studi Sistem Informasi, UNIPMA, Jl. Setiabudi No.85, Madiun, 63118 \\ E-mail: ridho.pamungkas@unipma.ac.id
}

\begin{abstract}
The library is a Technical Implementation Unit in tertiary institutions that has a role as a means of supporting the lecture process for students as well as media for gathering and disseminating information in the aspects of education, research aspects and aspects of community service to help achieve the Tri Dharma of Higher Education. Digital Library is the result of the role of information technology that provides convenience in providing information to users without being hindered by time and space. The aim of this research is to evaluate the digital library of Madiun University using the HOT-Fit Model (Human, Organizaton, Technology) method, which contains several variables, namely system quality, service quality, information quality, service use, service quality, system benefits and customer satisfaction . the results of this study as a whole can be seen the relationship between the three variables interplay between variables.
\end{abstract}

Keywords—: Digital Library; Evaluation; HOT-Fit Models; Digital Libraries; Information Systems.

\section{PENDAHULUAN}

Perpustakaan merupakan Unit Pelaksana Teknis dalam yang menjadi media dalam penyediakan informasi dalam Perguruan Tinggi, tetapi seiring dengan perkembangan teknologi informasi yang menuntut untuk mampu menyediakan informasi secara online atau dapat di akses di mana saja dan kapan saja menjadikan kelemahan perpustakaan konvensional. Digital Library (Perpustakaan digital) merupakan solusi dari kekurangan perpustakaan konvensional karena mempunyai koleksi yang tersedia dalam bentuk digital sehingga pengguna dapat mengakses informasi kapan saja dan di mana saja(Kadarsih, Pujianto, 2016)(Grafika \& Kampus, 2012).

Unit Pelaksana Teknis Perpustakaan Perguruan Tinggi merupakan lembaga yang memegang peran utama dalam mendapatkan dan menyebarkan informasi untuk kebutuhan dalam bidang akademik maupun bidang penelitian. Digital Library (Perpustakaan digital) merupakan gagasan untuk menjadikan informasi tersedia tidak hanya untuk pengguna dalam Perguruan Tinggi secara internal, namun juga dapat dipergunakan secara eksternal di seluruh dunia(Prabaningrum, Perpustakaan, \& 2016, 2016).

Banyak kemudahan yang diberikan dalam hal pengolahan data perpustakaan dengan penggunaan sistem informasi. Seperti pelayanan menjadi lebih baik, koleksi data secara keseluruhan yang ada lebih mudah di kontrol, mudah dalam mendapatkan informasi yang dibutuhkan oleh pengguna informasi. Meski demikian sistem informasi perpustakaan yang ada masih dianggap perlu pengembangan(Junaedi, 2018).

Perkembangan teknologi dan kebutuhan informasi yang menjadikan alasan kuat Unit Pelaksana Teknis Perpustakaan untuk melakukan pengembangan sistem informasi perpustakan yang lebih baik lagi memberikan kemudahan bagi admin maupun pengguna. Penggunaan digital library sudah banyak dipergunakan di perpustakaan pada perguruan tinggi yang bertujuan untuk memberikan kemudahan bagi pengguna perpustakaan dalam mendapatkan sebuah informasi(Pamungkas, 2016). Digital library (Perpustakaan digital) merupakan sebuah sistem yang memiliki berbagai layanan dan obyek informasi yang mendukung akses obyek informasi tesebut melalui media perangkat digital. Untuk mengetahui suatu sistem informasi dapat berjalan dengan baik dan sesuai dengan kebutuhan pengguna informasi perpustakaan digital, maka diperlukan evaluasi. Evaluasi dibutuhkan untuk semua sistem informasi yang akan dan pernah digunakan oleh pengguna. Hal ini dilaksanakan untuk melihat bagaimana capaian program atau kinerja yang telah dilakukan(Mulyadi \& Choliq, 2019)(Deharja \& Santi, 2018). Adapun metode yang dipergunakan dalam melakukan evaluasi Perpustakaan Digital Universitas PGRI Madiun adalah HOT (Human, Organization, Technology) FIT Model, yang menempatkan tiga unsur tersebut menjadi penting dalam sebuah sistem informasi yaitu Human/orang, Organization/organisasi dan technology/teknologi serta kesesuaian hubungan diantara tiga variabel tersebut(Mirabolghasemi, Choshaly, \& Iahad, 2019)(Nofikasari \& Sunyoto, 2017).

\section{METODE PENELITIAN}

Asosiatif kausal merupakan jenis penelitian yang dilakukan dalam penelitian ini. Penelitian asosiatif kausal adalah "penelitian yang bertujuan untuk menganalisis hubungan antara satu variabel dengan variabel lainya atau bagaimana suatu variabel mempengaruhi variabel lain”. Sehingga langkah yang akan dilakukan dalam penelitian ini adalah mengdentifikasi hubungan sebab akibat antar variabel-variabel, mencari tipe sesunguhnya dari fakta untuk membantu memhami dan 
memprediksi hubungan, serta menetapkan pendekatan kausal dari kejadian-kejadian yang berurutan dan mengukur variasi antara penyebab dan akibat yang diduga.

Penelitian ini menggunakan model Hot Fit untuk menilai keberhasilan penggunaan/implementas Perpustakaan Digital yang telah dikembangkan di penelitian sebelumnya pada Gambar1.

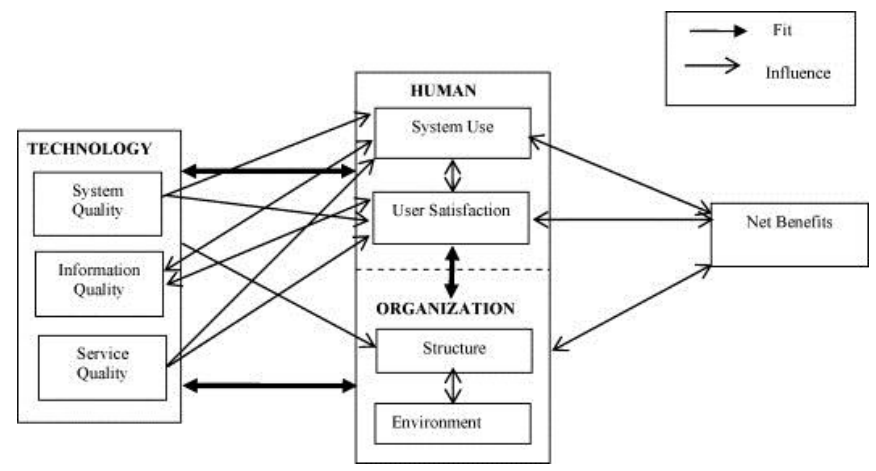

Gambar 1. HOT-Fit Model (Yusof, Paul, \& Stergioulas, 2006)

Pengembangan Model hipotesis yang akan digunakan untuk evaluasi sistem informasi perpustakaan digital berdasarkan HOT-FIT model dengan variabel Human Organization, Technology pada Gambar 2.

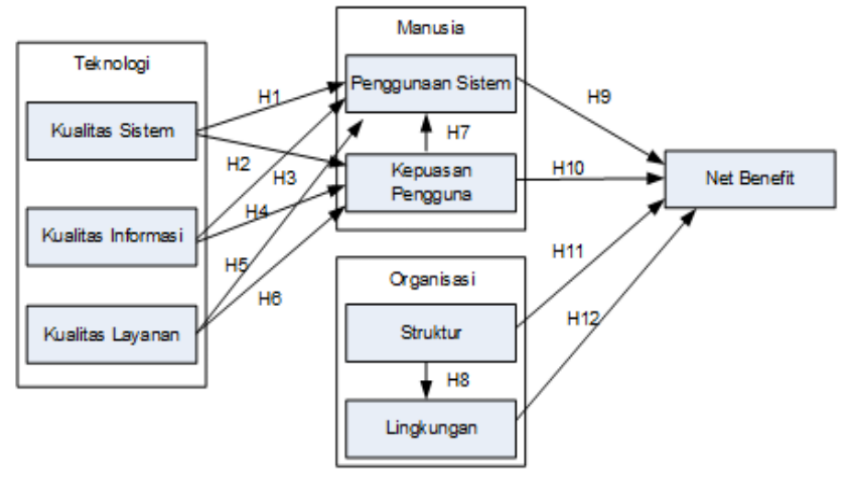

Gambar 2. Model Hipotesis Evaluasi Perpustakaan Digital.

Adapun penggunaan indicator variabel dalam penelitian ini dapat dilihat pada Tabel 1.

\begin{tabular}{|c|c|c|}
\hline Variabel & Indikasi Variabel & Kode \\
\hline \multirow{5}{*}{$\begin{array}{l}\text { KS (Kualitas } \\
\quad \text { Sistem) }\end{array}$} & Sistem mudah digunakan & KS01 \\
\hline & $\begin{array}{lcc}\text { Tampilan } & \text { Sistem } & \text { tidak } \\
\text { menimbulkan kebingungan } & \\
\end{array}$ & KS02 \\
\hline & $\begin{array}{l}\text { Terdapat password yang berbeda } \\
\text { tiap-tiap pengguna menjamin } \\
\text { kerahasiaan data }\end{array}$ & KS03 \\
\hline & $\begin{array}{l}\text { Kemudahan dalam mengakses } \\
\text { Sistem }\end{array}$ & KS04 \\
\hline & $\begin{array}{l}\text { Peluang Sistem mengalami error } \\
\text { rendah }\end{array}$ & KS05 \\
\hline \multirow{5}{*}{$\begin{array}{l}\text { KI (Kualitas } \\
\text { Informasi) }\end{array}$} & $\begin{array}{l}\text { Kesesuaian Informasi } \text { yang } \\
\text { dihasilkan dengan data } \\
\text { diinputkan tinggi. }\end{array}$ & $\mathrm{KI01}$ \\
\hline & Informasi yang dihasilkan valid & $\mathrm{KIO2}$ \\
\hline & $\begin{array}{l}\text { Informasi yang dihasilkan tepat } \\
\text { dan akurat }\end{array}$ & KI03 \\
\hline & $\begin{array}{l}\text { Informasi yang diperoleh detail } \\
\text { dan lengkap. }\end{array}$ & $\mathrm{KI04}$ \\
\hline & $\begin{array}{l}\text { Menghasilkan Informasi yang } \\
\text { mudah untuk dibaca }\end{array}$ & KI05 \\
\hline $\begin{array}{l}\text { KL (Kualitas } \\
\text { Layanan) }\end{array}$ & $\begin{array}{l}\text { Terdapat panduan dalam } \\
\text { penggunaan Sistem informasi }\end{array}$ & KL01 \\
\hline
\end{tabular}


PILAR TEKNOLOGI : Jurnal IImiah IImu-IImu Teknik

Website : http://pilar.unmermadiun.ac.id/index.php/pilarteknologi

\begin{tabular}{|c|c|c|}
\hline Variabel & Indikasi Variabel & Kode \\
\hline & $\begin{array}{l}\text { Layanan yang responsif dan cepat } \\
\text { dari pihak pengembang }\end{array}$ & KL02 \\
\hline & $\begin{array}{l}\text { Sistem dapat diakses dari mana } \\
\text { saja }\end{array}$ & KL03 \\
\hline \multirow{5}{*}{$\begin{array}{l}\text { PS (Penggunaan } \\
\quad \text { Sistem) }\end{array}$} & $\begin{array}{ll}\text { Penggunaan } & \text { Sistem } \\
\text { mempermudah dalam } & \text { proses } \\
\text { pencarian informasi } & \\
\end{array}$ & PS01 \\
\hline & $\begin{array}{l}\text { Penggunaan Sistem membantu } \\
\text { pekerjaan pengguna }\end{array}$ & PS02 \\
\hline & $\begin{array}{l}\text { Penggunaan dapat membantu } \\
\text { dalam mengambil keputusan }\end{array}$ & PS03 \\
\hline & $\begin{array}{l}\text { User memiliki keahlian dalam } \\
\text { penggunaan sistem informasi }\end{array}$ & PS04 \\
\hline & $\begin{array}{l}\text { Pengguna sangat tergantung } \\
\text { dengan Sistem informasi dalam } \\
\text { pekerjaan pengguna }\end{array}$ & PS05 \\
\hline \multirow{8}{*}{$\begin{array}{l}\text { KP (Kepuasan } \\
\text { Pengguna) }\end{array}$} & $\begin{array}{l}\text { fasilitas dan fitur-ftur yang ada } \\
\text { pada sistem } \quad \text { informasi } \\
\text { perpustakaan digital sudah sesuai } \\
\text { dengan kebutuhan pengguna }\end{array}$ & KP01 \\
\hline & $\begin{array}{ll}\text { Pengguna belum puas dan perlu } \\
\text { pengembangan serta } & \text { perbaikan } \\
\text { terhadap Sistem } & \text { informasi } \\
\text { perpustakaan digital } & \\
\end{array}$ & KP02 \\
\hline & $\begin{array}{l}\text { Semua fitur serta fungsi yang ada } \\
\text { pada Sistem informasi } \\
\text { perpustakaan digital telah berjalan } \\
\text { sesuai dengan kebutuhan }\end{array}$ & KP03 \\
\hline & $\begin{array}{l}\text { Informasi yang dihasilkan oleh } \\
\text { sistem informasi akurat sesuai } \\
\text { dengan kebutuhan pengguna }\end{array}$ & KP04 \\
\hline & Pengguna puas terhadap tampilan & KP05 \\
\hline & $\begin{array}{l}\text { Sistem Informasi Perpustakaan } \\
\text { Digital }\end{array}$ & \\
\hline & $\begin{array}{llr}\text { Secara } & \text { keseluruhan } & \text { Sistem } \\
\text { Informasi Perpustakaan } & \text { Digital } \\
\text { sesuai dengan harapan pengguna } \\
\text { untuk membantu tugas sehari-hari }\end{array}$ & KP06 \\
\hline & $\begin{array}{lcr}\text { Sistem } & \text { Informasi } & \text { Perpustakaan } \\
\text { Digital } & \text { Mudah } & \text { untuk } \\
\text { dipergunakan } & & \\
\end{array}$ & KP07 \\
\hline \multirow{5}{*}{$\begin{array}{c}\text { Struktur } \\
\text { Organisasi } \\
\text { (Organisation } \\
\text { Struktur) (SO) }\end{array}$} & \begin{tabular}{lcr}
\multicolumn{3}{l}{ Sistem Informasi yang diterapkan } \\
merupakan salah satu strategi \\
Perguruan & Tinggi & untuk \\
meningkatkan kinerja pengguna
\end{tabular} & $\mathrm{SO} 01$ \\
\hline & $\begin{array}{l}\text { Pihak lembaga melakukan } \\
\text { perbaharuan perangkat keras } \\
\text { maupun perangkat lunak yang } \\
\text { dibutuhkan oleh sistem. }\end{array}$ & $\mathrm{SO} 02$ \\
\hline & $\begin{array}{llr}\text { Penggunaan } & \text { sistem } & \text { telah } \\
\text { direncanakan dengan baik } & \text { oleh } \\
\text { pihak lembaga } & & \\
\end{array}$ & SO03 \\
\hline & $\begin{array}{l}\text { Pihak lembaga mendukung } \\
\text { penggunaan Sistem Informasi }\end{array}$ & $\mathrm{SO} 04$ \\
\hline & $\begin{array}{l}\text { Organisasi dapat menyediakan } \\
\text { dukungan fasilitas berupa } \\
\text { infrastrukur untuk mendukung } \\
\text { implementasi sistem Informasi }\end{array}$ & $\mathrm{SO} 05$ \\
\hline \multirow{3}{*}{$\begin{array}{l}\text { Lingkungan } \\
\text { Organisasi } \\
\text { (Environment) } \\
\quad(\mathrm{LO})\end{array}$} & $\begin{array}{l}\text { Mendapat dkungan keuangan dari } \\
\text { pihak mnajemen. }\end{array}$ & LO01 \\
\hline & $\begin{array}{l}\text { Dukungan dari Perguruan Tinggi } \\
\text { terkait }\end{array}$ & LO02 \\
\hline & Semua unit kerja mendukung & LO03 \\
\hline
\end{tabular}


PILAR TEKNOLOGI : Jurnal IImiah IImu-IImu Teknik

Website : http://pilar.unmermadiun.ac.id/index.php/pilarteknologi

\begin{tabular}{|c|c|c|}
\hline Variabel & Indikasi Variabel & Kode \\
\hline & $\begin{array}{lll}\text { serta } & \text { membantu }\end{array}$ & \\
\hline & penggunaan Sistem Informasi & \\
\hline \multirow{6}{*}{$\begin{array}{c}\text { Manfaat } \\
\text { (Net Benefit) } \\
\text { (M) }\end{array}$} & $\begin{array}{l}\text { Sistem dapat membantu tugas } \\
\text { pekerjaan pengguna }\end{array}$ & NB01 \\
\hline & $\begin{array}{l}\text { Sistem Informasi } r \text { dapat } \\
\text { meningkatkan efisiensi } \\
\text { pengekerjaan }\end{array}$ & NB02 \\
\hline & $\begin{array}{l}\text { Sistem dapat membantu dalam } \\
\text { pengambilan keputusan }\end{array}$ & NB03 \\
\hline & $\begin{array}{ll}\text { Sistem dapat membantu dalam } \\
\text { pencapaian } \\
\text { secara efektif }\end{array}$ & NB04 \\
\hline & $\begin{array}{l}\text { Sistem dapat meningkatkan } \\
\text { komunikasi antar bagian dalam } \\
\text { organisasi pengguna } \\
\text { informasi }\end{array}$ & NB05 \\
\hline & $\begin{array}{l}\text { Sistem membantu dalam } \\
\text { pencapaian tujuan dengan efisien } \\
\text { dan efektif }\end{array}$ & NB06 \\
\hline
\end{tabular}

\section{III.HASIL DAN PEMBAHASAN}

\section{A. Perpustakaan Digital Universitas PGRI Madiun.}

Perpustakaan Digital Universitas PGRI Madiun berbasis website diintegrasikan dengan sistem informasi perpustakaan berbasis dekstop. Sistem dapat di akses melalui alamat http://perpus.unipma.ac.id/. Perpustakaan Digital UNIPMA terdapat 2 versi yaitu versi windows dan versi android yang dapat di unduh melalui alamat https://kubuku.id/download/universitas-pgrimadiun/. pada Gambar 3.

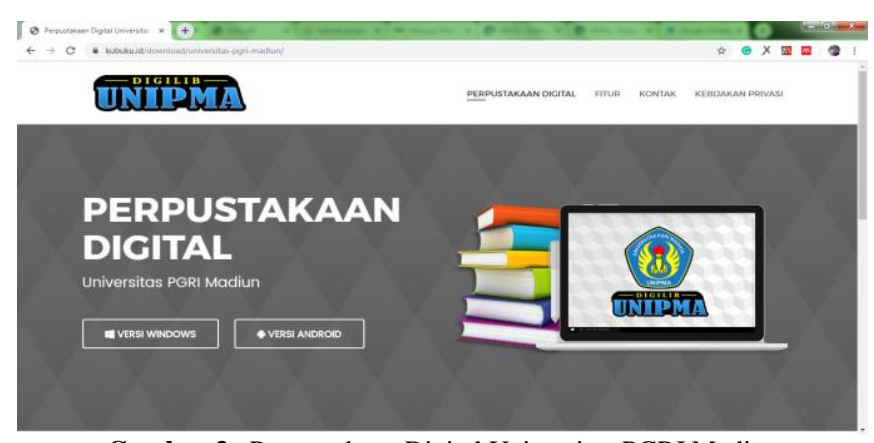

Gambar 3. Perpustakaan Digital Universitas PGRI Madiun

\section{B. Analisis Data serta Pengujian Model}

Sesuai dengan HOT-Fit model, penelitian ini memiliki beberapa variabel yaitu :

1. variabel eksogen

a.kualitas sistem (KS)

b.Kualitas informasi (KI)

c.Kualitas layanan $(\mathrm{KL})$

d.Struktur Organisasi (SO)

2. variabel endogen

a.Penggunaan Sistem (PS)

b.Kepuasan pengguna (KP)

c.Lingkungan Organisasi (LO)

d.Manfaat (M).

3. Variabel laten

a.kualitas sistem (KS)

b.Kualitas informasi (KI)

c.Kualitas layanan (KL)

d.Struktur Organisasi (SO)

e.Penggunaan (U)

f. Kepuasan pengguna (KP)

g.Lingkungan Organisasi (LO) 
h.Manfaat (M).

Tabel 2. Hasil uji t

\begin{tabular}{|c|c|c|c|c|c|}
\hline & $\begin{array}{l}\text { Original } \\
\text { Sample }\end{array}$ & $\begin{array}{c}\text { Sample } \\
\text { Mean }\end{array}$ & $\begin{array}{l}\text { Standart } \\
\text { Deviation }\end{array}$ & $\begin{array}{c}\text { Standart } \\
\text { Error }\end{array}$ & Uji T \\
\hline $\begin{array}{c}\text { KI } \\
\text { dengan } \\
\text { PS }\end{array}$ & 0,1803 & 0,2351 & 0,0645 & 0,3045 & $\begin{array}{c}2,353 \\
2\end{array}$ \\
\hline $\begin{array}{c}\text { KI } \\
\text { Dengan } \\
\text { KP }\end{array}$ & 0,6431 & 0,2604 & 0,4323 & 0,4250 & $\begin{array}{c}11,93 \\
43\end{array}$ \\
\hline $\begin{array}{c}\text { KL } \\
\text { dengan } \\
\text { PS }\end{array}$ & 0,3559 & $\begin{array}{c}- \\
0,0342\end{array}$ & 0,1141 & 0,5493 & $\begin{array}{c}6,502 \\
1\end{array}$ \\
\hline $\begin{array}{c}\text { KL } \\
\text { dengan } \\
\text { KP }\end{array}$ & 0,2243 & $\begin{array}{c}- \\
0,2309\end{array}$ & $-0,2350$ & 0,3432 & $\begin{array}{c}1,982 \\
3\end{array}$ \\
\hline $\begin{array}{c}\text { KP } \\
\text { dengan } \\
\text { PS }\end{array}$ & 0,8435 & 0,3045 & 0,3423 & 0,3559 & $\begin{array}{c}3,839 \\
2\end{array}$ \\
\hline $\begin{array}{c}\text { KP } \\
\text { dengan } \\
\text { NB }\end{array}$ & $-0,0734$ & 0,4250 & 0,5432 & 0,2243 & $\begin{array}{c}1,532 \\
3\end{array}$ \\
\hline $\begin{array}{c}\text { KS } \\
\text { dengan } \\
\text { PS }\end{array}$ & 0,5232 & 0,5493 & 0,0254 & 0,8435 & $\begin{array}{c}8,234 \\
4\end{array}$ \\
\hline $\begin{array}{c}\text { KS } \\
\text { dengan } \\
\text { KP }\end{array}$ & $-0,3433$ & 0,3432 & 0,5432 & 0,2351 & $\begin{array}{c}2,511 \\
9\end{array}$ \\
\hline $\begin{array}{c}\text { LO } \\
\text { dengan } \\
\text { NB }\end{array}$ & 1,1429 & $\begin{array}{c}- \\
0,3405\end{array}$ & 0,1902 & 0,2604 & $\begin{array}{c}3,325 \\
2\end{array}$ \\
\hline $\begin{array}{c}\text { PS } \\
\text { dengan } \\
\text { NB }\end{array}$ & 0,9304 & 0,3425 & 0,2349 & 0,0342 & $\begin{array}{c}5,239 \\
0\end{array}$ \\
\hline $\begin{array}{c}\text { SO } \\
\text { dengan } \\
\text { NB }\end{array}$ & 0,2489 & 0,3632 & 0,0153 & 0,1141 & $\begin{array}{c}55,92 \\
03\end{array}$ \\
\hline $\begin{array}{c}\text { SO } \\
\text { dengan } \\
\text { LO }\end{array}$ & 2,4923 & 1,9434 & 0,5234 & 0,5345 & $\begin{array}{c}12,43 \\
23\end{array}$ \\
\hline
\end{tabular}

Dari hasil uji t pada tabel 2 di atas dapat diketahui hipotesis ditolak maupun diterima dengan melihat nilai dari uji $\mathrm{t}$ dibandingkan dengan $t$ tabel, dalam pengujian hipotesis tingkat signifikansi adalah $94 \%(\alpha=0,05)$ nilai t tabel dengan tingkat signifikansi $94 \%$ adalah 1,86.

H1 : Kualitas Informasi (Informaton Quality) berpengaruh positif terhadap penggunaan sistem (System Use) Hasil uji t KI dengan PS memiliki nilai t hitung sebesar 2,35 nilai t hitung lebih besar dari t tabel sebesar 1,86 berarti H1 diterima atau terdapat pengaruh positif Information sistem (KI) terhadap penggunaan sistem (PS).

H2 : Kualitas Informasi (Information Quality) berpengaruh positif terhadap kepuasan pengguna (user satisfaction) Hasil uji t KI dengan KP memiliki nilai t hitung sebesar 11,93 nilai t hitung lebih besar dari nilai t tabel sebesar 1,86 berarti $\mathrm{H} 2$ diterima atau terdapat pengaruh positif antara kualitas Informasi (KI) dan kepuasan pengguna (KP).

H3 : Kualitas Layanan (Service quality) berpengaruh positif terhadap penggunaan sistem (System use). Hasil uji t KL dengan PS memiliki nilai sebesar 6,502 nilai $\mathrm{t}$ hitung lebih besar dari nilai t tabel sebesar 1,86 berarti $\mathrm{H} 3$ diterima atau terdapat pengaruh positif antara kualitas Layanan dan penggunaan sistem.

H4 : Kualitas Layanan (Service quality) berpengaruh positif terhadap kepuasan pengguna (User satisfaction) Hasil uji $t$ KI dengan KP memiliki nilai sebesar 1,98 nilai t hitung lebih besar dari nilai t tabel sebesar 1,86 berarti H4 diterima atau terdapat pengaruh positif antara kualitas informasi dan kepuasan pengguna 
H5 : Kepuasan Pengguna (User Satisfaction) berpengaruh positif terhadap penggunaan sistem (System use) Hasil uji t KP dengan PS memiliki nilai sebesar 3,83 nilai t hitung lebih besar dari nilai tabel sebesar 1,86 berarti H5 diterima atau terdapat pengaruh positif antara Kepuasan Pengguna terhadap penggunaan sistem.

H6 : Kepuasan Pengguna berpengaruh positif terhadap Manfaat (Net Benefit) Hasil uji t KP dengan NB memiliki nilai sebesar 1,53 nilai t hitung lebih besar dari nilai t tabel sebesar 1,86 berarti H6 diterima atau terdapat pengaruh positif antara Kepuasan Pengguna terhadap Manfaat.

H7 : Kualitas Sistem (System Quality) berpengaruh positif dan signifikan terhadap penggunaan sistem (system use) Hasil uji t KS dengan PS memiliki nilai sebesar 8,23 nilai t hitung lebih besar dari nilai t tabel sebesar 1,86 berarti $\mathrm{H} 7$ diterima atau terdapat pengaruh positif antara Kualitas Sistem terhadap penggunaan sistem.

H8 : Kualitas Sistem (KS) berpengaruh positif dan signifikan terhadap Kepuasan Pengguna (User Satisfaction) Hasil uji t KS dengan KP memiliki nilai sebesar 2,51 nilai t hitung lebih besar dari nilai t tabel sebesar 1,86 berarti $\mathrm{H} 8$ diterima atau terdapat pengaruh positif antara Kualitas Sistem terhadap Kepuasan Pengguna.

H9 : Lingkungan Organisasi (Environment) berpengaruh positif dan signifikan terhadap manfaat (net benefit) Hasil uji t LO dengan NB memiliki nilai sebesar 3,32 nilai t hitung lebih besar dari t tabel sebesar 1,86 berarti H9 diterima atau terdapat pengaruh positif antara Lingkungan Organisasi terhadap manfaat.

H10 : Penggunaan Sistem (system use) berpengaruh positif dan signifikan terhadap manfaat (net benefit) Hasil uji t PS dengan NB memiliki nilai 5,23 nilai t hitung lebih besar dari nilai t tabel sebesar 1,86 berarti H10 diterima atau terdapat pengaruh positif antara penggunaan sistem dengan manfaat.

H11 : Struktur organisasi berpengaruh positif dan signifikan terhadap manfaat. Hasil uji t SO dengan NB memiliki nilai 55,92 nilai t hitung lebih kecil dari 1,86 berarti $\mathrm{H} 11$ diterima atau terdapat pengaruh positif antara struktur organisasi dengan manfaat. H12 : Sturktur organisasi berpengaruh positif dan signifikan terhadap Lingkungan Organisasi. Hasil uji t SO dengan LO memiliki nilai 12,43 nilai t hitung lebih besar dari nilai t tabel sebesar 1,86 berarti $\mathrm{H} 12$ diterima atau terdapat pengaruh positif antara Sturktur organisasi terhadap Lingkungan organisasi.

\section{IV.KESIMPULAN}

Berdasarkan penelitan yang dilakukan maka dapat ditarik kesimpulan sebagai berikut :

a. Berdasarkan dari hasil uji untuk melihat variabel yang berpengaruh terhadap keberhasilan penggunaan Sistem Informasi Perpustakaan Digital Universitas PGRI Madiun adalah variabel Manusia, Organisasi, dan teknologi berpengaruh terhadap manfaat atau keberhasilan.

b. Penerapan Sistem Informasi Perpustakaan Digital belum sepenuhnya berhasil dalam penerapannya karena masih ada beberapa fitur dan tampilan sistem yang kurang sesuai atau kurang responsif oleh karena itu diperoleh rekomendasi yang dapat diberikan adalah bagian IT untuk melakukan perbaikan dan pengembangan atas sistem informasi perpustakaan digital.

c. Kualitas informasi, kualitas layanan dan Kualitas sistem, berpengaruh terhadap kepuasan pengguna hal ini dapat diartikan semakin meningkat Kualitas informasi, kualitas layanan dan Kualitas sistem maka akan meningkatkan kepuasan pengguna. Kepuasan pengguna akan berpengaruh terhadap manfaat atau net benefit hal ini berarti semakin meningkat kepuasan pengguna maka semakin tinggi net benefit atau keberhasilan yang didapatkan dari penggunaan Sistem Informasi Perpustakaan Digital.

\section{DAFTAR PUSTAKA}

Deharja, A., \& Santi, M. W. (2018). The evaluation of hospital information system management based on hot-fit model at rsu dr . h . koesnadi bondowoso 2018. Proceeding Book The 1st International on Food and Agriculture (ICoFA), O(0), 486-490. Diambil dari https://publikasi.polije.ac.id/index.php/ProceedingICOFA/article/view/1335

Grafika, J., \& Kampus, N. (2012). Evaluasi Perpustakaan Digital Perguruan Tinggi berdasarkan ... (Sasongko dan Hartanto). Prosiding SNST Fakultas Teknik, 1(1), 112-117. Diambil dari https://publikasiilmiah.unwahas.ac.id/index.php/PROSIDING_SNST_FT/article/view/1189

Junaedi, N. (2018). Analisa Kepuasan Mahasiswa Terhadap Sistem Informasi Perpustakaan Universitas Merdeka Madiun Menggunakan Framework Pieces. RESEARCH : Computer, Information System \& Technology Management, 1(2), 59-67. https://doi.org/10.25273/research.v1i02.3364

Kadarsih, Pujianto, M. A. (2016). Evaluasi Digital Library AMIK AKMI Baturaja Menggunakan HOT Fit Model. Annual Research Seminar 2016, 2(1), 414418. Diambil dari http://www.seminar.ilkom.unsri.ac.id/index.php/ars/article/view/949

Mirabolghasemi, M., Choshaly, S. H., \& Iahad, N. A. (2019). Using the HOT-fit model to predict the determinants of E-learning readiness in higher education: a developing Country's perspective. Education and Information Technologies, 1-22. https://doi.org/10.1007/s10639-019-09945-9

Mulyadi, D., \& Choliq, A. (2019). Penerapan Metode Human Organization Technology (HOT-Fit Model) untuk Evaluasi Implementasi Aplikasi Sistem Informasi Persediaan (SIDIA) di Lingkungan Pemerintah Kota Bogor. TeknoIS: Jurnal Ilmiah Teknologi Informasi dan Sains, 7(2), 1-12. https://doi.org/10.36350/jbs.v7i2.23

Nofikasari, I., \& Sunyoto, A. (2017). Evaluasi Penerapan Sistem Informasi Akademik Dengan Pendekatan Model Delone \& McLean, HOT FIT dan UTAUT (Studi Kasus: STMIK Duta Bangsa Surakarta). jurnal teknik informatika, 12(1), 81-90. Diambil dari http://ojs.udb.ac.id/index.php/dutacom/article/view/525

Pamungkas, R. (2016). RANCANG BANGUN APLIKASI PENJADWALAN KULIAH PADA STKIP WIDYA YUWANA. SEMNASTEKNOMEDIA ONLINE, 4(1), 4-11-121. Diambil dari https://ojs.amikom.ac.id/index.php/semnasteknomedia/article/view/1418/1345

Prabaningrum, U., Perpustakaan, A. D.-J. I., \& 2016, U. (2016). Evaluasi Jaringan Informasi Kearsipan Statis di Badan Arsip dan Perpustakaan Provinsi Jawa Tengah Tahun 2016. Ejournal3.Undip.Ac.Id, 5(2), 170-180. Diambil dari https://ejournal3.undip.ac.id/index.php/jip/article/view/15275

Yusof, M. M., Paul, R. J., \& Stergioulas, L. K. (2006). Towards a Framework for Health Information Systems Evaluation. In Proceedings of the 39th Annual Hawaii International Conference on System Sciences (HICSS'06) (hal. 95a-95a). IEEE. https://doi.org/10.1109/HICSS.2006.491 